RESEARCH PAPER RP1092

Part of Journal of Research of the National Bureau of Standards, Volume 20, May 1938

\title{
EFFECT OF CARBON ON THE CRITICAL COOLING RATE OF HIGH-PURITY IRON-CARBON ALLOYS AND PLAIN CARBON STEELS
}

\author{
By Thomas G. Digges
}

\section{ABSTRACT}

This report describes the preparation of a series of high-purity iron-carbon alloys and two series of plain carbon steels, the members of each series differing only in carbon content. Determinations of the austenitic grain size and critical cooling rates show how carbon affects the hardening properties and permit comparison of the hardenability of these alloys and steels.

\section{CONTENTS}

I. Introduction

II. Preparation of materials

1. Iron-carbon alloys_._.

2. Carbon steels

III. Microscopic examination

IV. Chemical composition _._. 576

V. Austenitic grain size

VI. Critical cooling rate_... 578

VII. Summary _._.

\section{INTRODUCTION}

The composition and grain size of austenite are now recognized as factors that influence the critical cooling rate or hardenability of steel. In previous investigations on the effect of carbon on the critical cooling rate, carried out at the National Bureau of Standards ${ }^{1}$ with plain carbon steels, and by other investiga tors ${ }^{2}$ with high-purity iron-carbon alloys, due regard was not given to the simultaneous influence of the austenitic grain size. At the time the study was made at the National Bureau of Standards, it was recognized that wide variation existed in the hardening characteristics of different heats of plain carbon steels of apparently the same composition, but the marked influence of austenitic grain size on the hardenability of steel was not then recognized. The experiments described in the present report were made to determine the influence of carbon on the critical cooling rate of both high-purity iron-carbon alloys and plain carbon steels. The method of preparing the alloys and steels used in this study eliminated the quality factor and variables other than carbon in the composition.

Determinations were made of the critical cooling rates for both

1 H. J. French and O. Z. Klopsch, Quenching diagrams for carbon steels in relation to some quenching media for heat treatment, Trans. Am. Soc. Steel Treating 6, 251-294 (1924).

${ }_{2} \mathrm{H}$. Esser, W. Eilender, and E. Spenle, Quenching diagrams of the iron-carbon alloys, Arch. Eisenhüttenw. 6, 389 - Esser, W. 
series of alloys and steels, quenched directly from the temperatures required to establish a constant austenitic grain size with all carbon in solution. In these experiments, the only variable that influenced the critical cooling rate was the carbon content of the austenite, since the time-temperature relationship used was such as to produce complete solution and uniform distribution of carbon in austenite of constant grain size. However, the study was extended to include determinations of the critical cooling rates of the carbon steels quenched from the usually recommended hardening temperature range. In the latter experiments, the carbon content and grain size of the austenite and total carbon varied with the different steels.

\section{PREPARATION OF MATERIALS}

\section{IRON-CARBON ALLOYS}

A heat of high-purity iron was used as the basic material for the iron-carbon alloys. This heat was prepared by melting and solidifying electrolytic iron in vacuo in a crucible of chemically pure magnesia bonded with a solution of 2 to 3 percent of magnesium chloride in

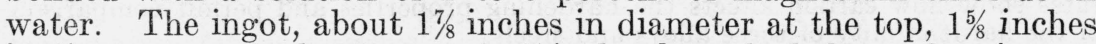
in diameter at the bottom, and 33/4 inches long, had the surface imperfections removed before being split longitudinally into two approximately equal sections preparatory to mechanical working. All the specimens of the iron-carbon alloys were prepared from this ingot.

Hot-working was carried out at an initial temperature of 2,100 to $2,200^{\circ} \mathrm{F}$, and the split halves of the original ingot were forged until reduced in thickness to about $3 / 16$ inch and then hot-rolled to bars about $1 / 8$ inch thick. The scale formed on the surface of the bars during hot-working was removed by grinding, before cold-rolling to the final form of plates, 0.040 inch thick. Prior to carburizing, these plates were cut into strips and annealed at $1,100^{\circ} \mathrm{F}$ for $\frac{1}{2}$ hour either in vacuo or in a reducing atmosphere, to remove the effects of cold-working.

The advantages of preparing high-purity iron-carbon alloys by carburization in gases have been pointed out by Mehl and Wells. ${ }^{3}$ They prepared a series of high-purity alloys from hydrogen-purified carbonyl iron by carburization in mixtures of dipentene-hydrogen and dipentene-benzene-hydrogen. These alloys were homogeneous in the carburized condition.

In the present experiments with propane as the carburizer, a study was made of the effects of temperature, rate of flow, concentration, direction of flow, and agitation of the gas on the uniformity of carburization of the iron. The preliminary carburizing experiments with propane as the carburizer gave unsatisfactory results. However, benzene proved to be entirely satisfactory for uniformly carburizing the iron to the desired carbon content.

Specimens of the high-purity iron were carburized in a mixture of hydrogen and benzene (less than 0.003 percent of sulfur) within the temperature range of 1,670 to $1,700^{\circ} \mathrm{F}$, with a gas flow of 90 to 100 milliliters per minute. The assembly of the apparatus used is shown in figure 1. The hydrogen was purified by passing it through Ascarite $(B)$ and silica gel $(D)$ contained in a vertical tube heated electrically to 1,300 to $1,475^{\circ} \mathrm{F}$, and then through magnesium perchlorate $(E)$ and phosphorus pentoxide $\left(F^{\prime}\right)$. The dry hydrogen next passed through

${ }^{3}$ R. F. Mehl and Cyril Wells, Consitution of high-purity iron-carbon alloys, Metals Tech. T. P. 798, 4 (June 1937). 
the benzene $(G)$ maintained at a temperature of 60 to $65^{\circ} \mathrm{F}$ by a water bath $(I)$ in a Dewar flask $(H)$, then through the orifice $(K)$ and around the specimen $(M)$ suspended vertically in a quartz tube by a wire of the same material as the specimen, and finally into the air at the exhaust end $(N)$ of the furnace.

The desired gas flow was maintained during carburizing by regulating the pressure of the system, as indicated by the oil manometer $(\boldsymbol{J})$, with reducing and needle valves attached to the hydrogen tank.

The furnace, constructed especially to obtain uniform heating of the specimens, consisted essentially of an Alundum tube wound with Nichrome wire, with a compensating coil placed at each end of the furnace over the main heating coil. The temperature was adjusted and controlled by independent adjustment of the current in each of the three branches of the heating circuit. By preliminary tests made

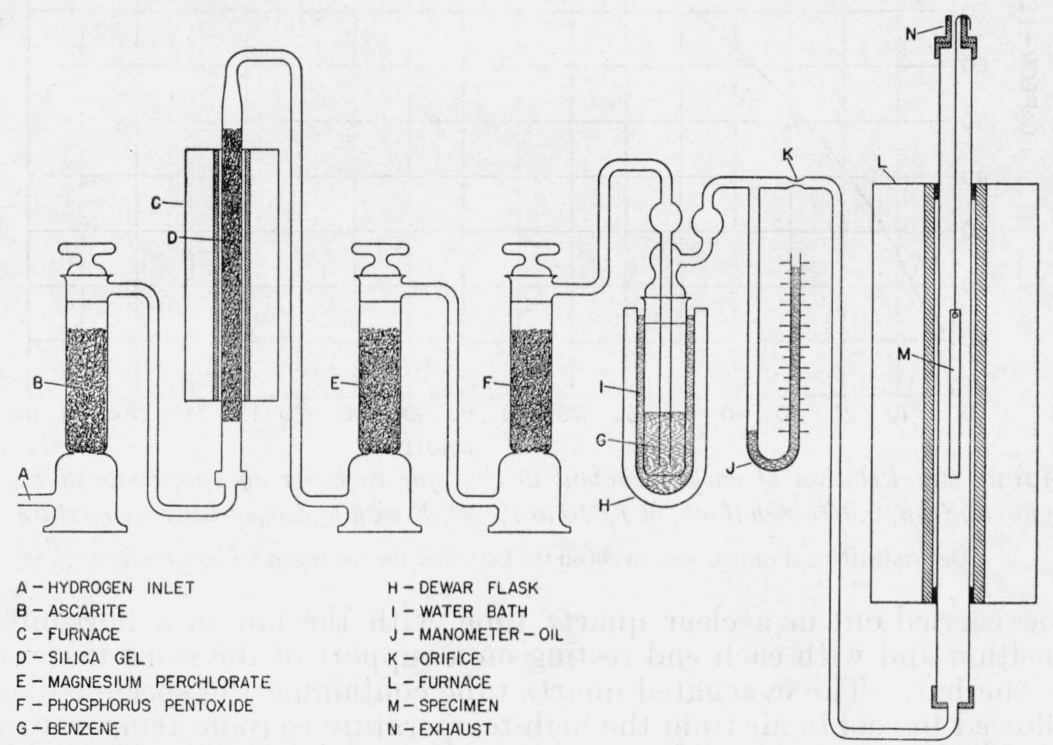

FiguRE 1.-Diagram of apparatus used for carburizing with hydrogen-benzene mixture.

prior to the carburizing treatment, the conditions necessary for establishing a uniform temperature were determined, and the current input necessary for maintaining equilibrium at the desired temperature was ascertained. The procedure for carburizing was as follows: After obtaining a uniform temperature in the carburizing zone of the furnace with the gas flowing at the required rate, the high-purity iron specimen ( 0.040 to 0.041 by 0.275 to 0.300 by 8 inches long) cleaned with $1 \mathrm{G}$ emery paper and washed in xylene, was inserted in the cold zone of the quartz tube at the top of the furnace. After remaining in this zone 1 to 2 minutes, the specimen was lowered without touching the walls of the tube into the carburizing zone, held for a predetermined time, and returned to the cold zone to cool in a reducing atmosphere to an estimated temperature of 200 to $400^{\circ} \mathrm{F}$. It was finally allowed to cool to room temperature in air. The time of carburizing varied with the desired carbon content of the alloy, as is shown in figure 2 . 
The carburized bars were ground to a width of $0.250 \mathrm{inch}$, by removing approximately equal amounts from each edge, before being heated in vacuo at 1,670 to $1,700^{\circ} \mathrm{F}$ for 4 to 5 hours to produce uniform distribution of the carbon in the cross section. This heat treatment

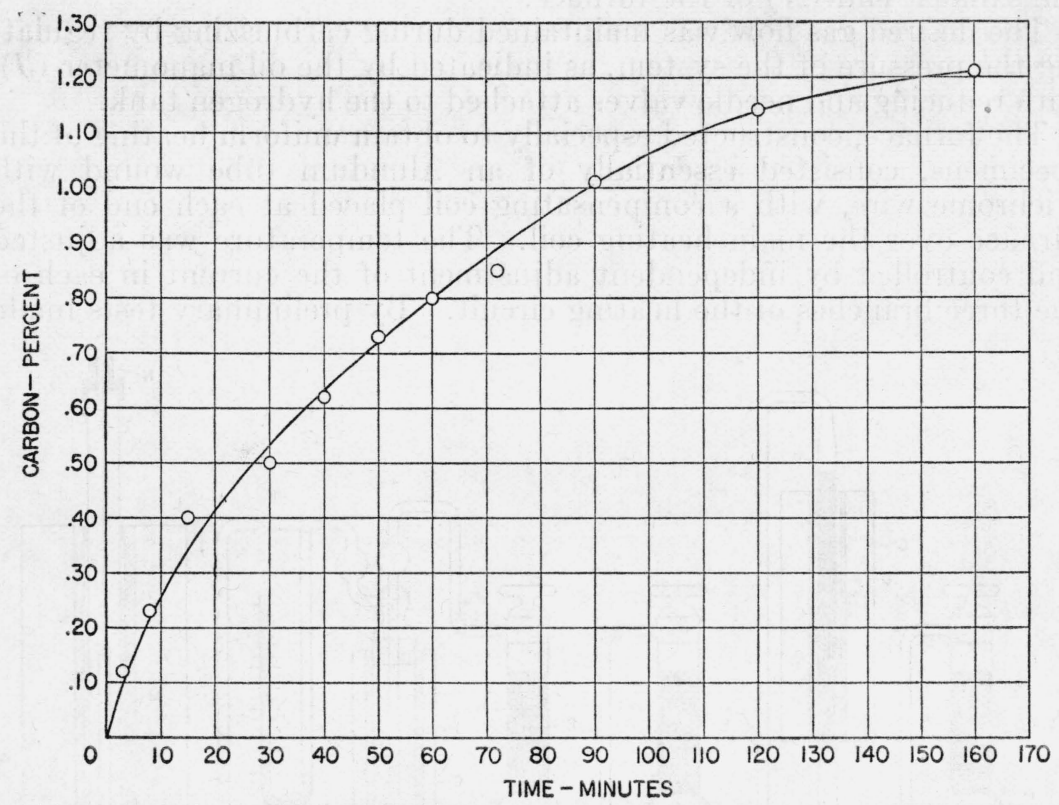

FIGURE 2.-Relation of carbon content to time for carburizing specimens of high. purity iron, 0.040 inch thick, at 1,670 to $1,700^{\circ} \mathrm{F}$ with hydrogen-benzene mixture.

Determinations of carbon were made on the bars after the treatment for homogeneity.

was carried out in a clear quartz tube, with the bar in a horizontal position and with each end resting on a support of the same material as the bar. The evacuated quartz tube containing the specimen was allowed to cool in air from the high temperature to room temperature. This cooling was sufficiently rapid to form sorbite (or fine pearlite) in the alloys, as is shown for the 0.23- and 1.21-percent carbon alloys in figure 3 . Specimens subsequently used for the determination of the austenitic grain size and critical cooling rate had this initial structure of sorbite.

\section{CARBON STEELS}

A forging, 2 inches in diameter, of acid open-hearth steel containing 0.20 percent of carbon was the starting material for the preparation of the plain carbon steels. The composition of the forging is shown in table 1.

TABLE 1.-Chemical composition of the steel used as the basic material for the carbon steels

\begin{tabular}{|c|c|c|c|}
\hline Element & Analysis & Element & Analysis \\
\hline $\begin{array}{l}\text { Carbon } \\
\text { Manganese } \\
\text { Phosphorus. } \\
\text { Sulfur. } \\
\text { Silicon }\end{array}$ & $\begin{array}{c}\text { Percent (by } \\
\text { weight) } \\
0.20 \\
.46 \\
.043 \\
.025 \\
.15\end{array}$ & $\begin{array}{l}\text { Chromium } \\
\text { Vanadium } \\
\text { Nickel } \\
\text { Copper } \\
\text { Arsenic }\end{array}$ & $\begin{array}{c}\text { Percent }(b y \\
\text { weight) } \\
0.02 \\
\text { Trace } \\
0.11 \\
.021 \\
.012\end{array}$ \\
\hline
\end{tabular}




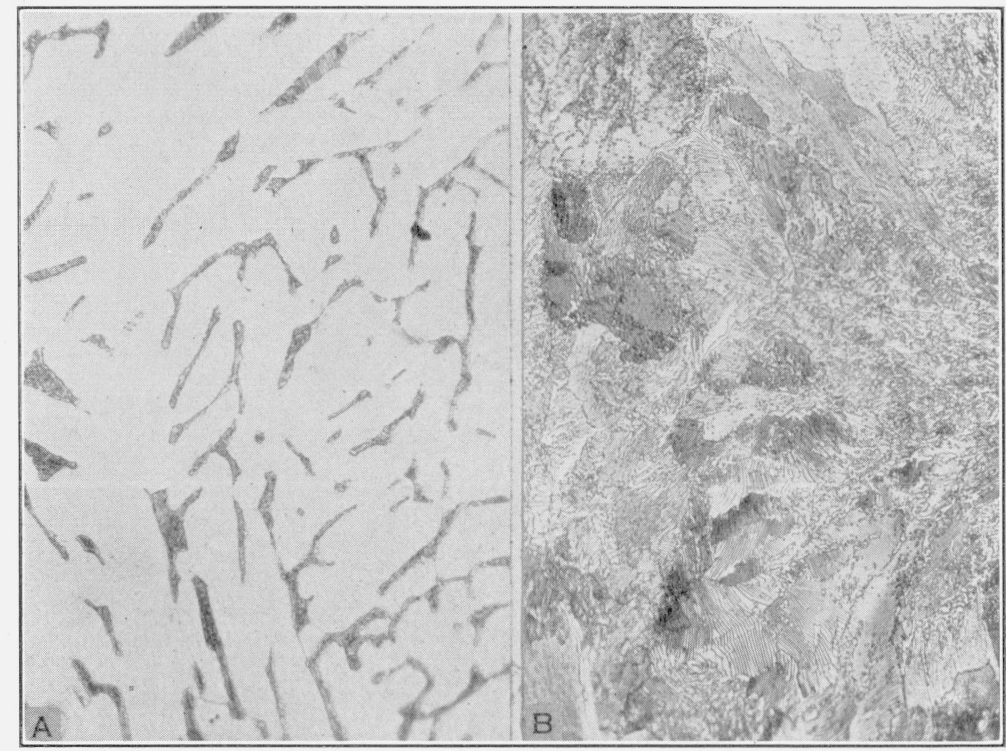

FIGURE 3.-Structure of iron-carbon alloys after treatment for homogeneity.

$A, 0.23$ percent of carbon; $B, 1.21$ percent of carbon. The sorbite, or fine pearlite, is representative of the initial structure of the alloys and steels for the determination of austenitic grain size and critical cooling rate. Etched with 1-percent nitric acid in alcohol. $\times 500$. 


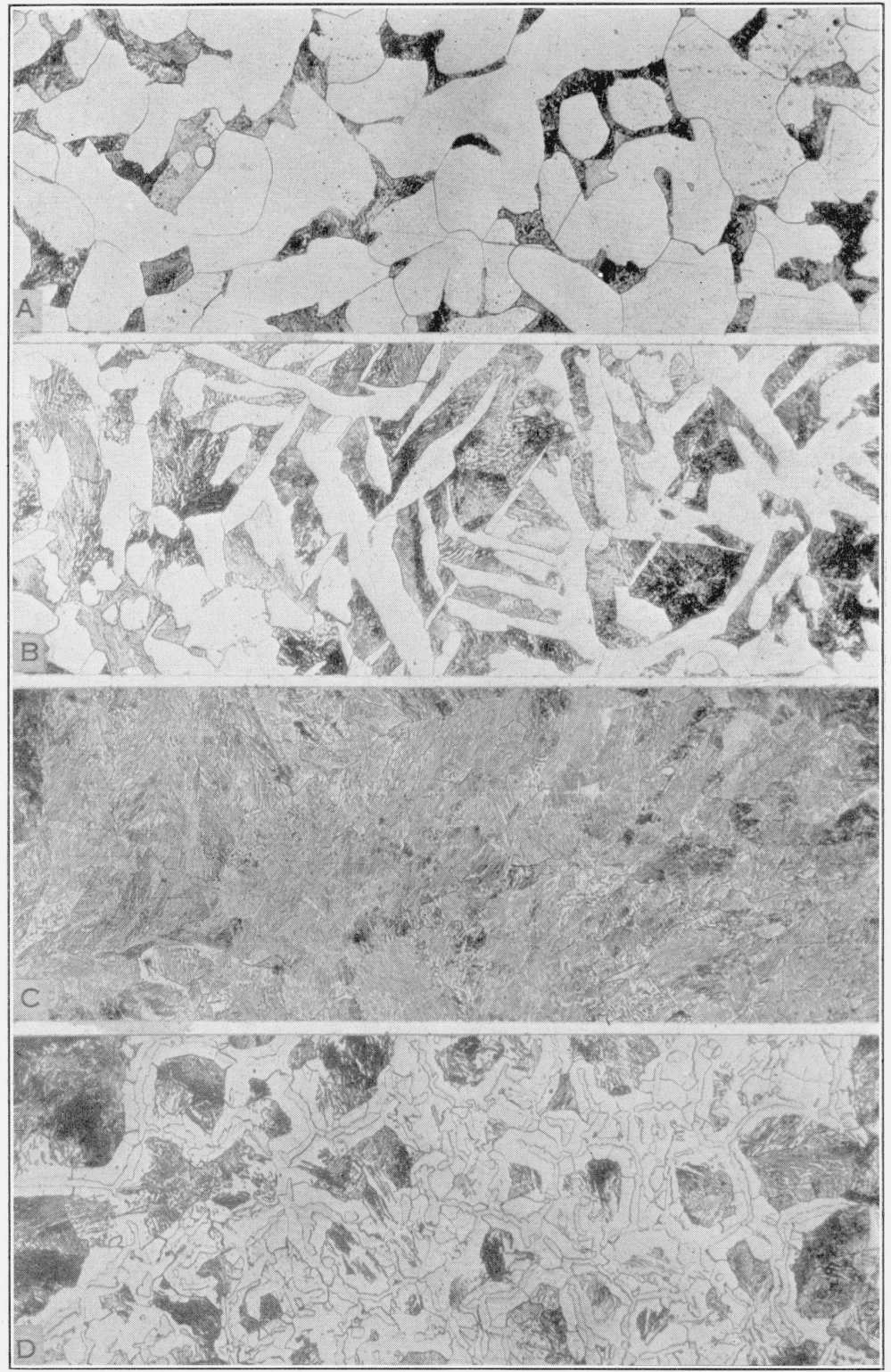

FIGURE 4.-Structure of annealed iron-carbon alloys.

$A, 0.23$ percent of carbon; $B, 0.50$ percent of carbon; $C, 0.85$ percent of carbon; $D, 1.21$ percent of carbon. Specimens annealed at $1,700^{\circ} \mathrm{F}$. for 1 hour in vacuo after treatment for homogeneity. The length of the micrographs represents practically the entire thickness of the bars. The left border of the micrographs shows the structure at the extreme edge of the specimens. Etched with equal parts of nitric acid (1 percent) and picric acid (5 percent) in alcohol. $\times 100$. 
To minimize the influence of segregation, a $5 / 8$-inch hole was drilled along the horizontal axis of this forging before preparing the specimens for carburizing. A disk from the cross section of the forging etched in hot acid showed no indications of segregation. However, subsequent microscopic examinations of the structures of the quenched specimens used in the determination of the critical cooling rates showed, in some of these specimens, indications of segregation of manganese sulfide inclusions or banding of ferrite and carbide. This factor evidently was responsible for the wide variation later observed in the structures of a few of the specimens prepared and quenched under identical conditions.

Two series of carbon steels were prepared from specimens cut from this forging. The first series was prepared by pack-carburizing specimens, 0.050 by 0.260 by 8 inches long, in a mixture of approximately 85 percent of wood charcoal and 15 percent of barium carbonate at $1,700^{\circ} \mathrm{F}$ for various periods of time. The carburized specimens were then pack-annealed at $1,700^{\circ} \mathrm{F}$ for 4 to 5 hours before normalizing from the usually recommended temperature range. The normalizing treatment produced a structure of sorbite in all the steels. The bars with this initial structure of sorbite were then ground to a thickness of 0.040 inch and a width of 0.250 inch, before preparing specimens for the determinations of the austenitic grain size and critical cooling rate.

With the procedure used in preparing the steels by pack-carburizing, pack-annealing, and normalizing difficulty was encountered in obtaining steels of the desired carbon content with the carbon uniformly distributed. Furthermore, pack-carburized specimens often show an appreciable increase in the oxygen content. Because of these factors, the second series of carbon steels was prepared by carburizing specimens of the 0.20-percent carbon steel in hydrogen and benzene, and homogenizing by heating in vacuo. These treatments were carried out under the same procedure as that already described for the highpurity iron-carbon alloys. Cooling the 0.040 -inch-thick bars from the temperature used in the homogenizing treatment was sufficiently rapid to form sorbite in all the steels. The specimens subsequently used for determination of the austenitic grain size and critical cooling rate had this initial structure.

\section{MICROSCOPIC EXAMINATION}

Pieces, $1 / 4$ to $3 / 8$ inch long, were discarded from each end of all the bars after the treatments for homogeneity. Microscopic examination of the cross section of each end of the bars (after the end pieces were removed) showed the carbon to be uniformly distributed. This is illustrated for the gas-carburized alloys and steels in figure 4, which shows the microstructure of four of the iron-carbon alloys annealed at $1,700^{\circ} \mathrm{F}$ for 1 hour in vacuo after the treatment for homogeneity. These micrographs show the structure of the bar from one surface almost to the opposite surface. (The actual cross sections were 0.040 to 0.041 inch thick.) This annealing treatment produced "abnormal" structures in all of the hypereutectoid iron-carbon alloys, as shown in the 1.21-percent carbon alloy by the coalesced masses of cementite partially or entirely surrounded by ferrite. 


\section{CHEMICAL COMPOSITION}

Spectrochemical and chemical analyses were made on specimens of the iron-carbon alloys and the determinations of gas content were made by the vacuum-fusion method. The are spectrum of the alloy was examined for the sensitive lines of $\mathrm{Ag}, \mathrm{Al}, \mathrm{As}, \mathrm{Au}, \mathrm{B}, \mathrm{Ba}, \mathrm{Be}, \mathrm{Bi}, \mathrm{Ca}$, $\mathrm{Cb}, \mathrm{Cd}, \mathrm{Ce}, \mathrm{Co}, \mathrm{Cr}, \mathrm{Cu}, \mathrm{Fe}, \mathrm{Ga}, \mathrm{Ge}, \mathrm{Hf}, \mathrm{Hg}, \mathrm{In}, \mathrm{Ir}, \mathrm{K}, \mathrm{Li}, \mathrm{Mg}, \mathrm{Mn}$, Mo, Na, Ni, Os, Pb, Pd, Pt, Rh, Ru, Sb, Sc, Si, Sn, Sr, Ta, Th, Ti, $\mathrm{Tl}, \mathrm{U}, \mathrm{V}, \mathrm{W}, \mathrm{Y}, \mathrm{Zn}$, and $\mathrm{Zr}$. The elements found present other than iron were $\mathrm{Ca}, \mathrm{Co}, \mathrm{Cu}, \mathrm{Mg}, \mathrm{Mn}, \mathrm{Ni}, \mathrm{Pb}$, and $\mathrm{Si}$ (table 2).

TABLE 2.-Impurities determined in the iron-carbon alloys

\begin{tabular}{|c|c|c|c|}
\hline \multirow{2}{*}{ Element } & \multicolumn{3}{|c|}{ Analysis ${ }^{1}$ (percent by weight) } \\
\hline & $\begin{array}{l}\text { Spectro- } \\
\text { chemical }\end{array}$ & Chemical & $\begin{array}{l}\text { Vacuum } \\
\text { fusion }\end{array}$ \\
\hline $\begin{array}{l}\text { Manganese } \\
\text { Phosphorus. }\end{array}$ & & $\begin{array}{r}0.002 \\
<.001\end{array}$ & \\
\hline Sulfur & 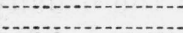 & $\begin{array}{r}<.001 \\
.004\end{array}$ & \\
\hline $\begin{array}{l}\text { Silicon- } \\
\text { Copper-.- }\end{array}$ & 0.001 & .002 & 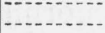 \\
\hline Copper. & $<.001$ & Not detected & $-\cdots$ \\
\hline Nickel_-_- & .006 & .007 & \\
\hline Calcium & $<.001$ & .006 & (-....... \\
\hline Lead & probably $<.001$ & $-\cdots+$ & - \\
\hline Oxygen & & & 0.003 \\
\hline \multirow{2}{*}{$\begin{array}{l}\text { Nitrogen } \\
\text { Hydrogen }\end{array}$} & & & .001 \\
\hline & & & .0002 \\
\hline
\end{tabular}

${ }_{1}$ Determinations were made on specimens from the bars after carburizing and heat treatment for homogeneity except as follows: Values of nickel, cobalt, and copper by chemical analysis were obtained from the electrolytic iron prior to melting, and the values of manganese and phosphorus by chemical analysis were obtained from the bars as carburized. Spectrochemical analyses were made by B. F. Scribner, chemical analyses by $W$. H. Jukkola and J. L. Hague, and vacuum-fusion analyses by V. C. F. Holm, ail members of the staff of the National Bureau of Standards.

2 Spectrum lines of cobalt and manganese were also found.

Chemical analyses of the electrolytic iron before and after vacuum fusion and of the carburized alloys showed no increase in silicon, sulfur, or manganese in the various operations incident to the preparation of the alloys. Likewise, analyses by the vacuum-fusion method showed no difference in the oxygen, nitrogen, or hydrogen contents as a result of working or carburizing of the high-purity iron.

The results of the analyses, given in table 2 , show that sulfur, nickel, cobalt, and oxygen were the major impurities contained in the alloys. These elements amounted to about 0.021 percent, whereas the total percentage (by weight) for all impurities determined was about 0.030 .

Carbon was also determined in specimens cut from opposite ends of the $7 \frac{1}{2}$-inch bars. Some of the alloys had the same carbon content at both ends. Maximum variation in the carbon value determined in any of the alloys was 0.04 percent. This, however, was an extreme case, and it is believed that the values for carbon for the entire bar are within 0.01 or 0.02 percent of the values shown in the various figures given in this report. In the alloys prepared later and in some of the carbon steels, the carbon was determined in only one section. This was adjacent to the specimens used for the determination of austenitic grain size and critical cooling rate.

Determinations of carbon in specimens from opposite ends of eight different carbon steels, prepared by carburizing in hydrogen and ben- 


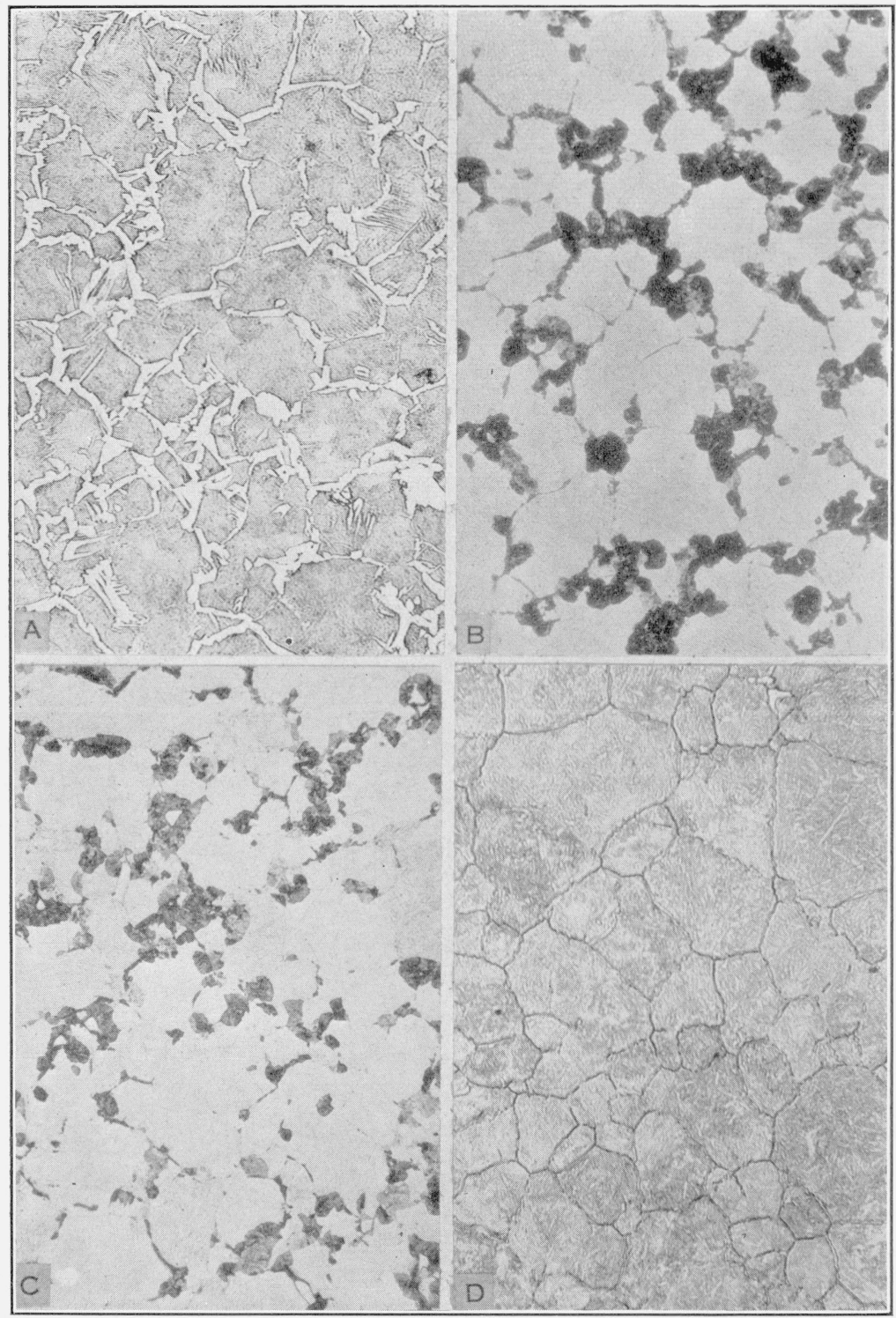

FIGURE 5.-Grain size of iron-carbon alloys at $1,700^{\circ} \mathrm{F}$.

$A, 0.23$ percent of carbon; $B, 0.62$ percent of carbon; $C, 1.01$ percent of carbon; $D, 1.21$ percent of carbon. A ustenitic grain size of 6 to 12 grains per square inch at 100 diameters (ASTM grain number 4). Etched with 1-percent nitric acid in alcohol. $\times 100$. 


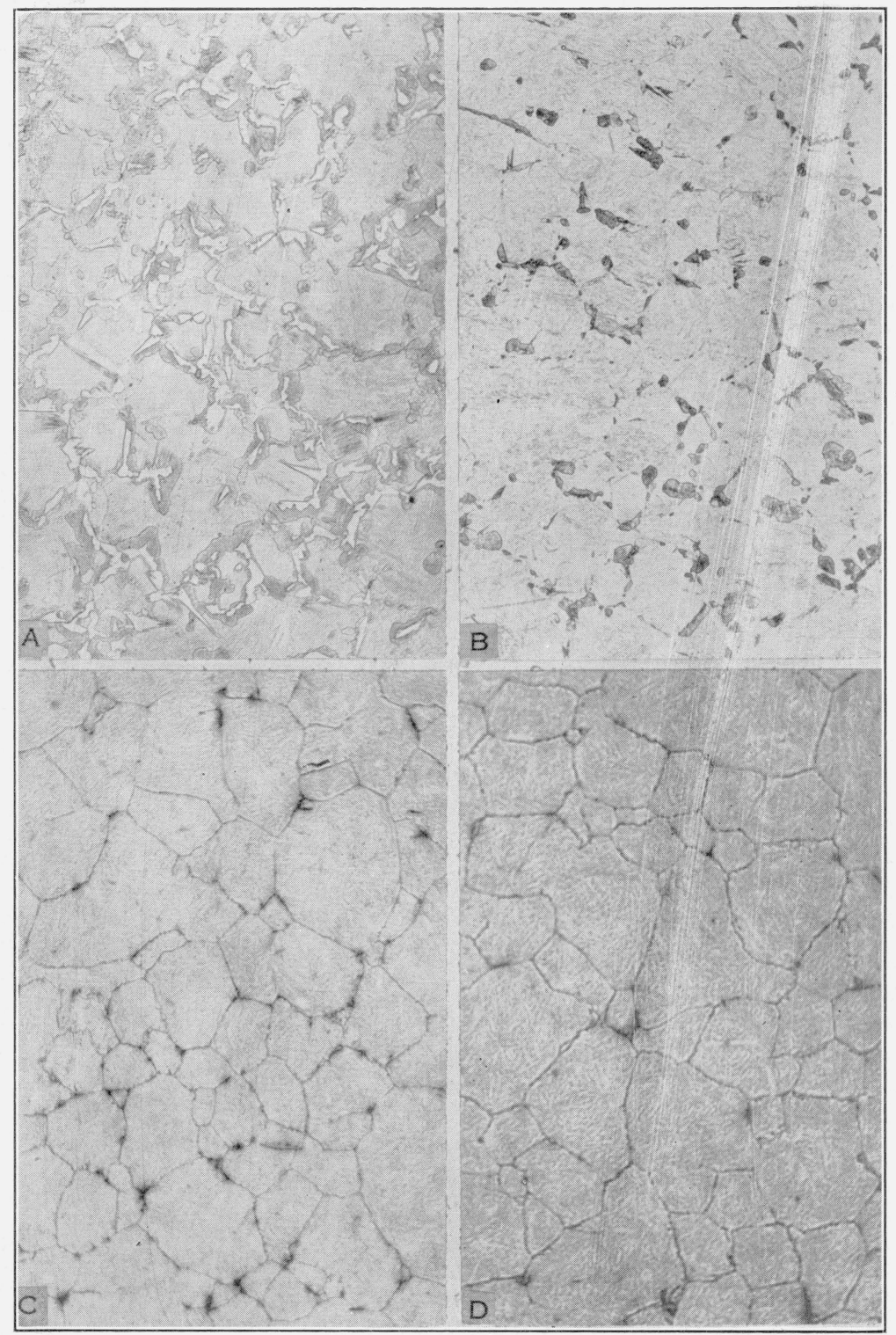

FIGURE 7.-Grain size of carbon steels at different temperatures.

$A, 0.46$ percent of carbon; $B, 0.76$ percent of carbon; $C, 1.10$ percent of carbon; $D, 1.15$ percent of carbon A verage grain size of 6 to 12 grains per square inch at 100 diameters at $1,625^{\circ} \mathrm{F}$ for the 0.46 percent of carbon, $1,660^{\circ} \mathrm{F}$ for the 0.76 percent of carbon, $1,680^{\circ} \mathrm{F}$ for the 1.10 percent of carbon, and $1,700^{\circ} \mathrm{F}$ for the 1.15-percent carbon steel. Etched with 1-percent nitric acid in alcohol. $\times 100$. 
zene, showed a maximum difference of 0.03 percent in any one steel. Variations in carbon of this same magnitude were also shown in the annealed bars of the selected steels, which were prepared by packcarburizing. Further minor changes occurred in the carbon content of some of the latter steels during the normalizing treatment. The values determined after this treatment were used in preparing the various diagrams for this series of steels.

Complete analyses were not made on the carbon steels after the carburizing and homogenizing treatments. The proportions of the elements other than carbon, given in table 1, should not be materially affected by the various steps incident to the preparation of these steels. Possibly, the oxygen content varied for steels prepared by pack-carburizing. Variations in the oxygen content, however, had no detectable influence on the critical cooling rate of the steels.

\section{AUSTENITIC GRAIN SIZE}

The specimens for the determination of the austenitic grain size had the same initial structure and were of the same shape and size as

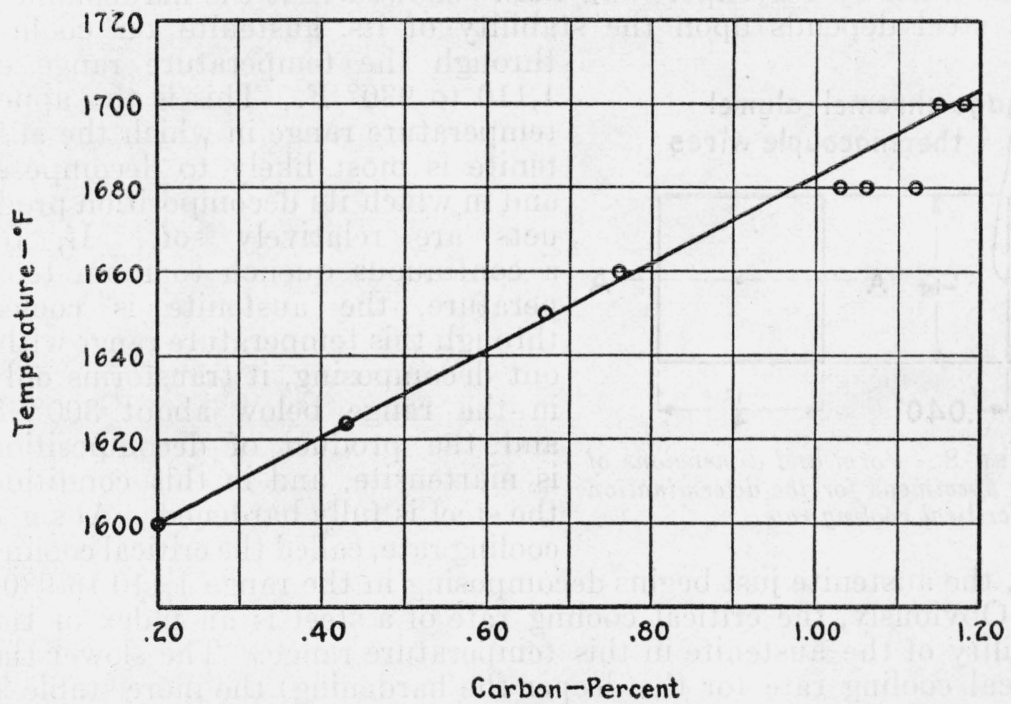

FIGURE 6.-Relation of temperature to carbon content of the steels for establishing austenitic grain size of 6 to 12 grains per square inch at 100 diameters.

those used for the determination of the critical cooling rate. They were heated in the same manner, held for the same time at the same temperature, and were then cooled in a manner suitable for outlining the grains.

The austenitic grain size at $1,700^{\circ} \mathrm{F}$ was determined for the highestcarbon alloy (1.21 percent of carbon). This temperature was sufficiently high to dissolve all the carbon. Subsequent tests on the lowercarbon alloys showed that variations in carbon did not affect the grain size at this selected temperature of $1,700^{\circ} \mathrm{F}$.

Each of the iron-carbon alloys had an average grain size of 6 to 12 grains per square inch at 100 diameters (ASTM grain number 4) at 
$1,700^{\circ} \mathrm{F}$. Figure 5 shows 1.21-percent carbon alloys at $1,700^{\circ} \mathrm{F}$. The grain size at $1,700^{\circ} \mathrm{F}$ was also determined for the 1.18-percent carbon steel. As shown in figure 6 , lower temperatures were necessary to establish the same average grain size of 6 to 12 grains per square inch at 100 diameters in the lower carbon steels. Figure 7 shows that this grain size was obtained at $1,625^{\circ} \mathrm{F}$ for the 0.46 -percent carbon steel, at $1,660^{\circ} \mathrm{F}$ for the 0.76 -percent carbon steel, at $1,680^{\circ} \mathrm{F}$ for the 1.10 -percent carbon steel, and at $1,700^{\circ} \mathrm{F}$ for the 1.15 -percent carbon steel.

On heating within the usually recommended hardening temperature range, specimens of the hypoeutectoid carbon steels had approximately the same average grain size of 12 to 24 grains per square inch at 100 diameters (ASTM grain number 5).

No differences were observed between the temperature-grain-sizecritical-cooling-rate relations of the carbon steels prepared by packcarburizing and those prepared by carburizing in hydrocarbon.

\section{CRITICAL COOLING RATE}

The work by Davenport and Bain ${ }^{4}$ showed that the hardenability of a steel depends upon the stability of its austenite on cooling

22 gage chromel-alumel

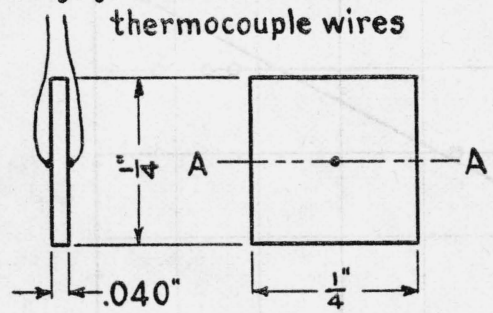

Figure 8.-Form and dimensions of the specimens for the determination of critical cooling rate. through the temperature range of 1,110 to $930^{\circ} \mathrm{F}$. This is the upper temperature range in which the austenite is most likely to decompose, and in which its decomposition products are relatively soft. If, by a continuous quench to room temperature, the austenite is cooled through this temperature range without decomposing, it transforms only in the range below about $300^{\circ} \mathrm{F}$ and the product of decomposition is martensite, and in this condition the steel is fully hardened. At some cooling rate, called the critical cooling rate, the austenite just begins decomposing in the range 1,110 to $930^{\circ}$ F. Obviously, the critical cooling rate of a steel is an index of the stability of the austenite in this temperature range. The slower the critical cooling rate (or the deeper the hardening) the more stable is its austenite in the temperature range 1,110 to $930^{\circ} \mathrm{F}$. In the present experiments, the critical cooling rate was taken as the average cooling rate between 1,110 and $930^{\circ} \mathrm{F}$, which produced in the quenched specimen a structure of martensite with nodular troostite (fine pearlite) in amounts estimated to be between 1 and 3 percent.

For the determination of the critical cooling rate, specimens 0.25 inch square by 0.040 inch thick were quenched directly from the temperatures establishing the austenitic grain size. One wire of a 22-gage Chromel-Alumel thermocouple was spot-welded to the center of the flat face of the specimen and the other wire was spot-welded to the center of the opposite face (fig. 8). The specimens were heated in an atmosphere of nitrogen at a rapid rate, approximately 1 minute

4 E. S. Davenport and E. C. Bain, Transformation of austenite at constant subcritical temperatures, Trans. Am. Inst. Mining Met. Engrs., Iron and Steel Div. 90, 117-154 (1930). 
being required to reach the desired temperature, held at that temperature for 15 minutes, and quenched in a bath which sealed the bottom end of the vertical tube of the heating furnace.

To minimize oxidation, the end of the furnace tube extending into the quenching bath was either closed by means of a slide, or the bath was covered with a layer of quenching oil during the entire time of heating the specimens of all the alloys and steels prepared by carburizing with hydrogen and benzene. This procedure was modified for the steels prepared by pack-carburizing. Specimens of the latter steels, quenched from the usually recommended hardening temperature range, were heated in an atmosphere of nitrogen, and those quenched from temperatures establishing a constant austenitic grain size were heated in an atmosphere of nitrogen and illuminating gas.

The desired cooling rates were obtained by quenching either in oil or in a sodium-silicate-water bath of varying concentration.

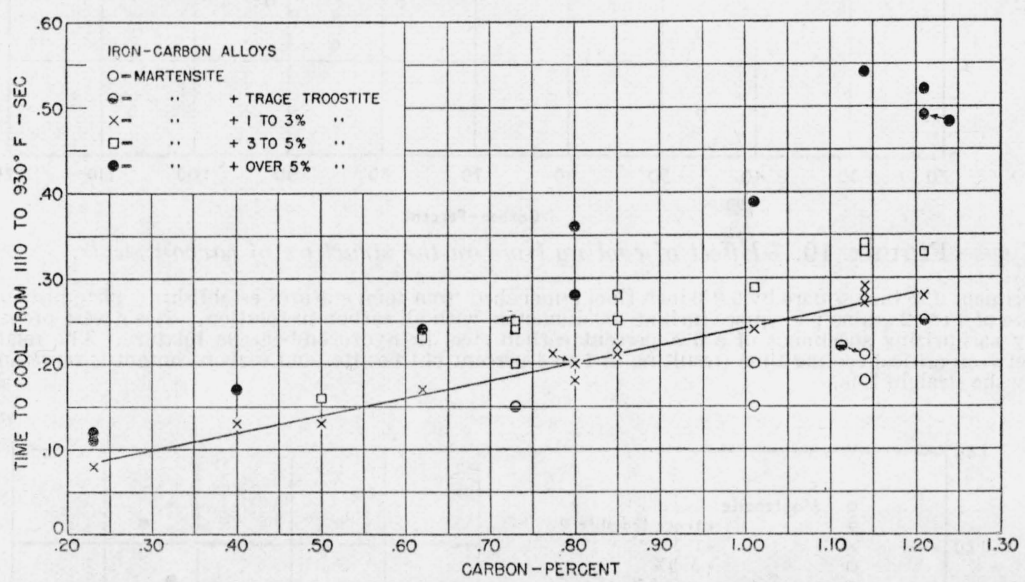

FiguRe 9.-Effect of cooling time on the structure of iron-carbon alloys.

Specimens 0.25 inch square by 0.040 inch thick, quenched from $1,700^{\circ} \mathrm{F}$, the temperature establishing austenitic grain size of 6 to 12 grains per square inch at 100 diameters with all carbon in solution. The relation between cooling time (resulting in 1 to 3 percent of troostite) and carbon content is represented by the straight line.

The bath was at approximately room temperature at the time of quenching. A photographic time-temperature cooling curve was obtained during the quench by means of a string-galvanometer apparatus described in a previous report. ${ }^{5}$

For the correlation of critical cooling rate with structure, microscopic examinations were made of the quenched specimens on the cross section of the 0.040 -inch-thick sheet, a short distance from the point of contact of the thermocouple wires (fig. 8).

The critical cooling rate was determined for iron-carbon alloys, ranging in carbon from 0.23 to 1.21 percent, and for carbon steels, ranging in carbon from 0.43 to 1.18 percent. Each specimen was quenched directly from the temperatures establishing a constant austenitic grain size with all the carbon in solution.

The relation between the time to cool from 1,110 to $930^{\circ} \mathrm{F}$ and the carbon content is shown for the iron-carbon alloys in figure 9 , for the

\footnotetext{
${ }^{5} \mathrm{H}$. J. French and O. Z. Klopsch, Quenching diagrams for carbon steels in relation to some quenching media for heat treatment, Trans. Am. Sor. Steel Treating 6, 251-294 (1924).
} 


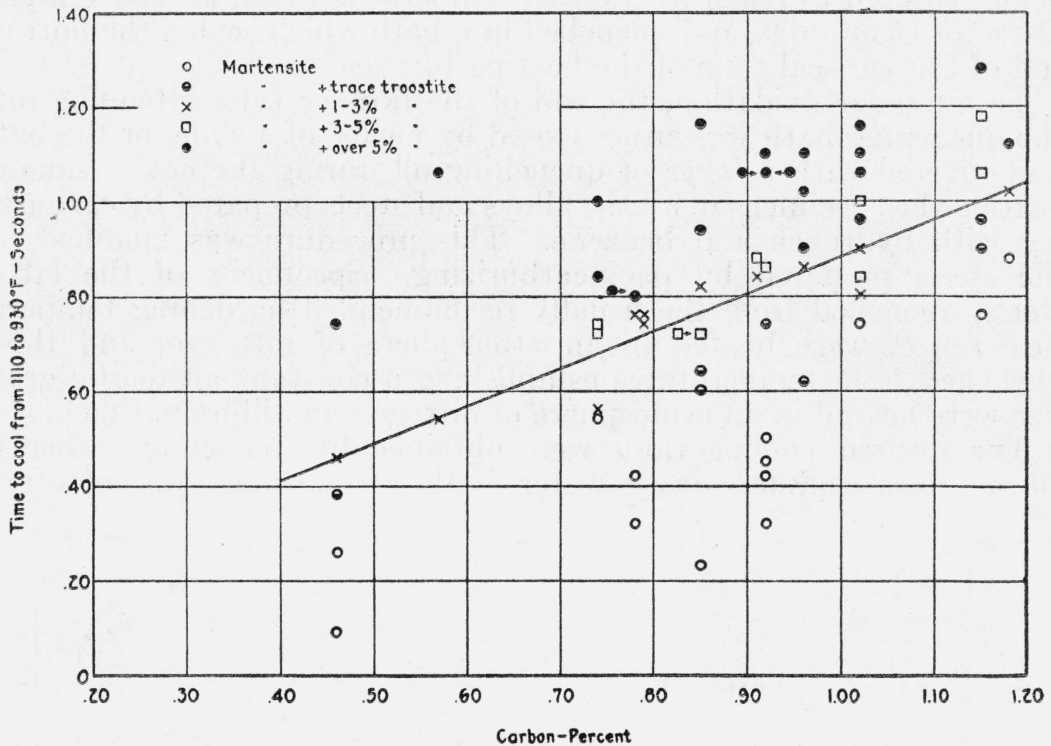

Figure 10.-Effect of cooling time on the structure of carbon steels.

Specimens 0.25 inch square by 0.040 inch thick, quenched from temperatures establishing austenitic grain size of 6 to 12 grains per square inch at 100 diameters with all carbon in solution. Steels were prepared by carburizing specimens of a 0.20 -percent carbon steel in hydrogen-benzene mixture. The relation between critical cooling time (resulting in 1 to 3 percent of troostite) and carbon content is represented by the straight line.

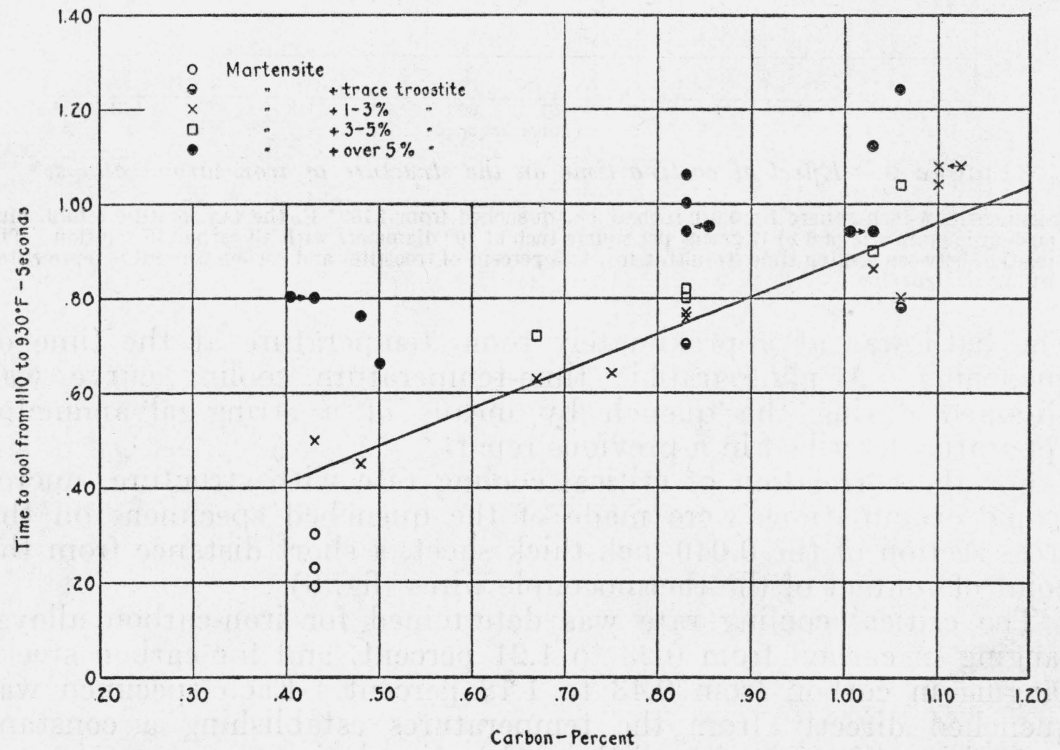

FIGURE 11.-Effect of cooling time on the structure of carbon steels.

Specimens 0.25 inch square by 0.040 inch thick, quenched from temperatures establishing austenitic grain size of 6 to 12 grains per square inch at 100 diameters. Steels were prepared by pack-carburizing specimens of a 0.20 -percent carbon steel. The relation between critical cooling time (resulting in 1 to 3 percent of troostite) and carbon is represented by the straight line. 
steels prepared by carburizing in hydrogen and benzene in figure 10 , and for the steels prepared by pack-carburizing in figure 11. The estimated amounts of nodular troostite formed ( 1 to 3 percent for critical cooling time) with the various quenching rates are also shown in the figures, together with the curves representing the relation of critical cooling time to the carbon content.

The critical cooling rate was also determined for the carbon steels, varying in carbon from 0.43 to 1.38 percent, quenched from the usually recommended hardening temperatures. For these experiments, the austenitic grain size of the hypoeutectoid steels was constant (ASTM grain number 5) and all carbon was in solution. For the hypereutectoid steels the carbon content of the austenite

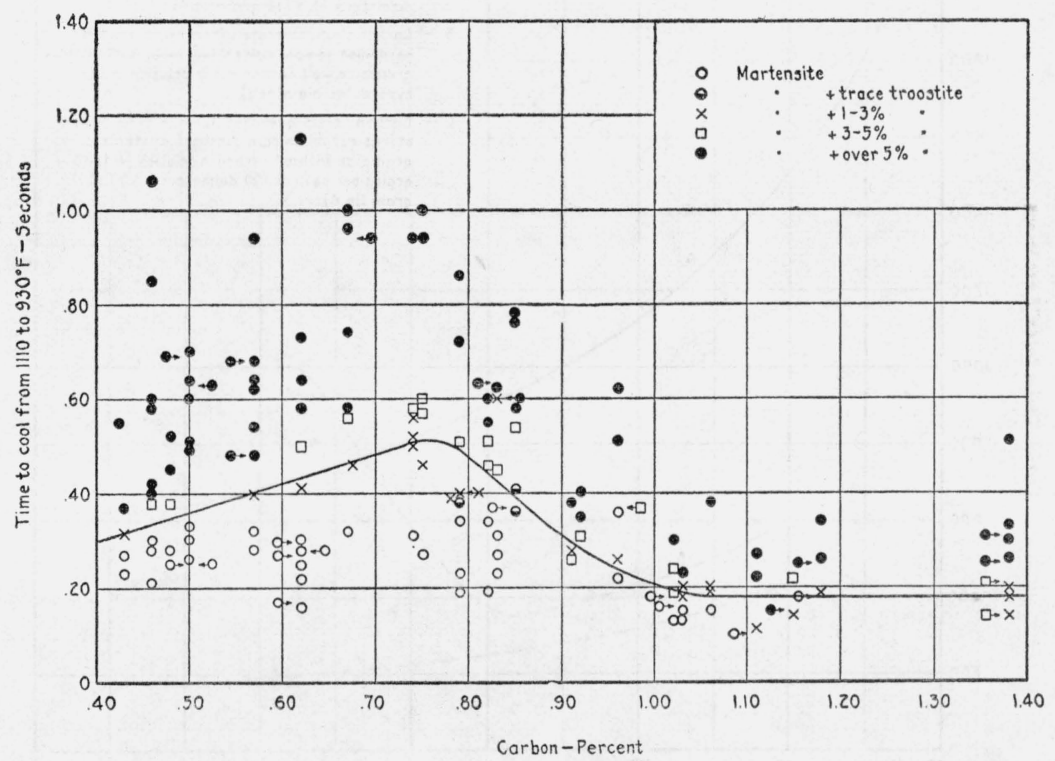

FIGURE 12.-Effect of cooling time on the structure of carbon steels.

Specimens 0.25 inch square by 0.040 inch thick, quenched from the usually recommended hardening temperature range. Steels were prepared by either pack-carburizing, or carburizing in hydrogen-benzene mixture, specimens of a 0.20 -percent carbon steel. The relation between critical cooling time (resulting in 1 to 3 percent of troostite) and carbon content is represented by the curve.

was constant, but not all carbon was in solution and the average austenitic grain size was smaller than that of the hypoeutectoid steels. The critical cooling rates in these experiments, therefore, were influenced by three variables, namely, austenitic grain size, carbon content of austenite, and total carbon.

For the steels quenched from the usually recommended hardening temperatures, the relation between the time to cool from 1,110 to $930^{\circ} \mathrm{F}$ and the carbon content is shown in figure 12 .

For convenient comparison, the relations of the critical cooling rate to carbon content of the alloys and steels are summarized in figure 13. For the selected conditions of constant austenitic grain size and solution of all carbon in the austenite, the critical cooling rate decreased continuously with increase in carbon, for both the high-purity ironcarbon alloys (curve $A$ ) and the plain carbon steel (curve $C$ ). That 
is, the hypereutectoid alloys had slower critical cooling rates (were deeper hardening) than the alloys of either eutectoid or hypoeutectoid compositions, and the hypereutectoid steels were deeper hardening than the steels of eutectoid and hypoeutectoid compositions. However, the effect of a small change in carbon content of the austenite of the lower-carbon alloys and steels on the critical cooling rate was more marked than a corresponding change in the higher-carbon alloys and steels. For example, an increase in carbon from 0.23 to 0.33 percent of the alloys decreased the critical cooling rate by about $450^{\circ} \mathrm{F}$ per

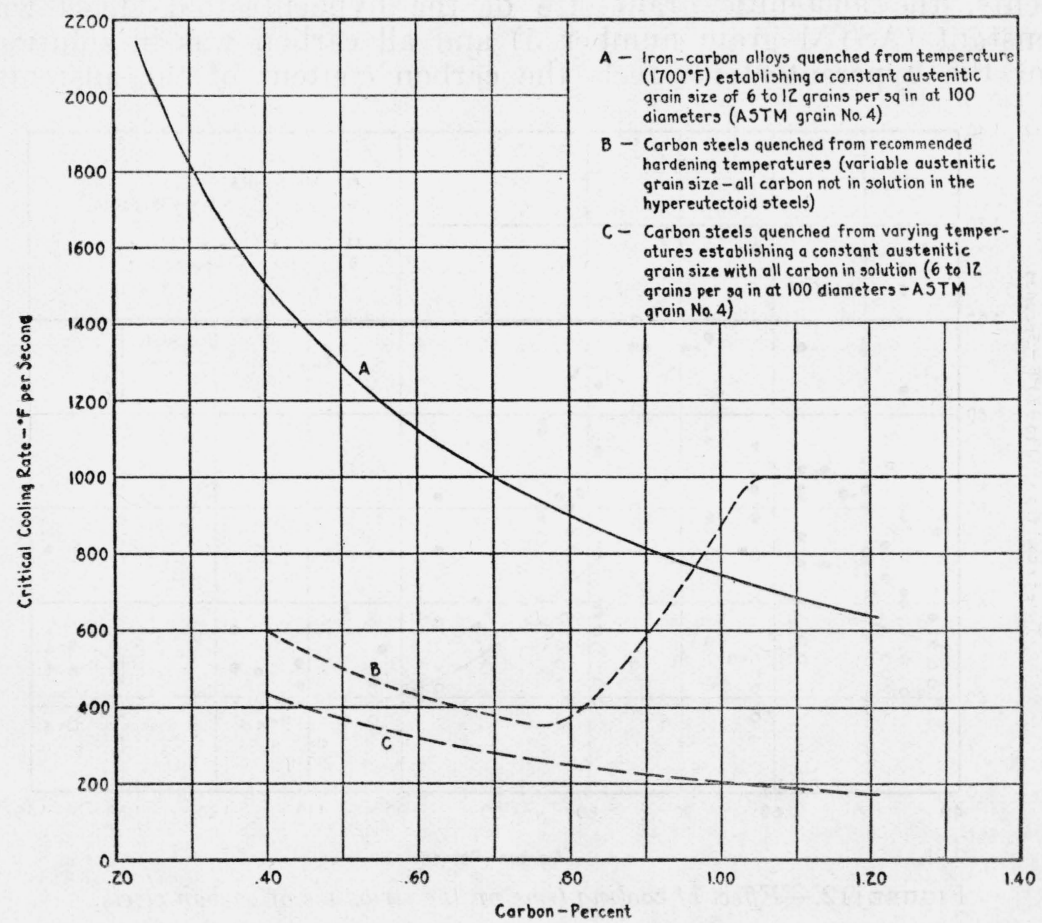

FIGURE 13.-Relation of critical cooling rate to carbon content of the iron-carbon alloys and carbon steels.

second, whereas an increase in carbon from 1.10 to 1.20 percent decreased the critical cooling rate only about $50^{\circ} \mathrm{F}$ per second.

An important feature brought out in these experiments, therefore, is the influence of the carbon content of the austenite on hardenability. Since this was the only variable in the experiments on critical cooling rates of the alloys, the differences observed in their hardenability must be attributed to this factor. Likewise, the differences observed in the hardenability of the plain carbon steels (curve $C$ ) are also due solely to differences in carbon content of the austenite.

Comparisons of the critical cooling rates of the alloys and steels under similar conditions with respect to austenitic grain size, carbon content, and all carbon in solution (curves $A$ and $C$, respectively) show that the alloys had considerably higher rates, that is, they were comparatively shallow hardening. For any selected carbon content 
within the range investigated, and with austenitic grain size of 6 to 12 grains per square inch at 100 diameters, the ratio of the critical cooling rate of the alloys to that of the steels was approximately constant, and was of the order of 3.5 to 1 .

The high-purity iron-carbon alloys differ from the plain carbon steels in the number of nonmetallic inclusions and amounts of manganese. The high-purity alloys were relatively free from nonmetallic inclusions and manganese. The carbon steels contained a relatively large number of nonmetallic inclusions and about 0.46 percent of manganese. These factors produce opposite effects on the critical cooling rate or hardenability. Nonmetallic inclusions act as nuclei for transformation of the austenite on cooling and thus tend to promote shallow hardening, whereas elements such as manganese and chromium stabilize the austenite or retard its rate of decomposition and thus contribute to deep hardening. The manganese content, obviously, was the dominant of these two factors in controlling the reaction rates and has imparted to the steels comparatively deephardening properties.

For the carbon steels quenched from the usually recommended hardening temperature range (curve $B$ ), the critical cooling rate decreased with increase in carbon up to about 0.75 or 0.80 percent; thereafter the critical cooling rate increased rapidly with increase in carbon up to about 1.05 percent. Further increase in carbon from about 1.05 to 1.40 percent had no appreciable influence on the critical cooling rate. Thus, the steel of about eutectoid composition had the minimum critical cooling rate, or was deeper hardening, than either the steels of hypoeutectoid or hypereutectoid compositions. As already stated, these critical cooling rates (curve $B$ ) were influenced by variations in austenitic grain size and carbon content of austenite, as well as by total carbon.

In these experiments, the average austenitic grain size was approximately constant and all carbon was in solution at the time of quenching the steels ranging in carbon from about 0.40 to 0.75 percent. The difference in their hardenability was caused by a difference in the carbon content of the austenite. With carbon in excess of about 0.80 percent, the carbon content of the austenite remained constant (quenching temperature of $1,425^{\circ} \mathrm{F}$ ), but differences existed in the grain size, and in the undissolved or total carbon. The undissolved carbon or free carbides not only retard grain growth but also (like nonmetallic inclusions) act as nuclei for transformation during cooling. Furthermore, the reaction rate of the austenite is influenced by the number, size, and distribution of the free carbides. Assuming unformity in distribution and size of the carbide particles, the number will vary directly with increase in carbon above the saturation value for carbon in austenite at the quenching temperature. With steels containing carbon slightly above the eutectoid value, the free carbide particles, although relatively few in number, were sufficient to increase materially the reaction rates. The reaction rates continued to increase uniformly and rapidly as the number of free carbide particles increased until a value finally was reached (corresponding to a total carbon value of about 1.05 percent) beyond which further increase in the number of carbide particles had no marked effect on the critical cooling rate or hardenability. That is, the rapid increase in critical cooling rate with increase in carbon from about 0.80 to 1.05 percent 
was due principally to variations in the number of free carbide particles.

The marked differences in critical cooling rates of the hypereutectoid steels (curves $B$ and $C$ of fig. 13) were caused by differences in austenitic grain size and undissolved carbides at the time of quenching. On heating to the usually recommended hardening temperature, the austenitic grain size was relatively small and some carbon remained undissolved. Both these factors contribute to shallow hardening. Obviously, to utilize full hardening power of the steel, it is necessary to heat the steel to a temperature sufficiently high to insure complete solution of the carbon.

This is further illustrated by comparison of the critical cooling rates of the hypereutectoid alloys and steels (curves $A$ and $B$, respectively). As already shown, under similar conditions, the alloys were comparatively shallow hardening. However, the hypereutectoid alloys with the larger grain size and with all carbon in solution had slower critical cooling rates (were deeper hardening) than the carbon steels of similar total carbon content quenched from the recommended hardening temperature range.

The important role of austenitic grain size in controlling hardenability is shown by comparison of the critical cooling rates of the hypoeutectoid steels (curves $B$ and $C$ for carbon ranging from 0.40 to 0.75 percent). For a given carbon content within the range of 0.40 to 0.75 percent, the steel differed only in the size of the austenite grains at the time of quenching. The critical cooling rates represented by curve $B$ were obtained with specimens having an average of 12 to 24 grains per square inch at 100 diameters (ASTM grain number 5) and those by curve $C$, with 6 to 12 grains per square inch at 100 diameters, (ASTM grain number 4). The smaller grain size steels obviously required the higher critical cooling rates. For example, increasing the average austenitic grain size from ASTM grain number 5 to 4 decreased the critical cooling rate of the 0.65 -percent carbon steel from about 400 to $300^{\circ} \mathrm{F}$ per second, or by about $100^{\circ} \mathrm{F}$ per second. This change in critical cooling rate is equivalent to that resulting from increasing the carbon in solution from 0.45 to 0.65 percent (constant austenitic grain size of 6 to 12 grains per square inch at 100 diameters).

Attempts were also made to determine the critical cooling rate of the basic steel (table 1 ) used in preparing the carbon steels. For an austenitic grain size of 6 to 12 grains per square inch at 100 diameters the critical cooling rate of this 0.20 -percent carbon steel would be expected to be in the neighborhood of 800 to $900^{\circ} \mathrm{F}$ per second. In fact, some of the experimental results showed it to be within this range. However, similar tests in which the specimens were cooled at considerably higher rates, observed values up to $12,000^{\circ} \mathrm{F}$ per second, produced in the quenched specimens some areas containing free ferrite. In the latter tests, the ferritic areas in the quenched specimens resulted from nonuniform distribution of the carbon in the austenite at the time of quenching. Regardless of cooling rates, complete hardening of these particular specimens should not be obtained until the ferrite or at least the very low carbon areas in the austenite were eliminated.

A structure containing nodular troostite was not observed in any of the quenched specimens of this particular 0.20 -percent carbon steel. If transformation of the austenite on cooling occurred at temperatures 
above the range where martensite was formed, then the transformation product was free ferrite, not nodular troostite. With the 0.23-percent carbon alloy, the transformation product was nodular troostite.

Results of investigations of the effect of carbon on critical cooling rate have been reported by Esser, Eilender, and Spenle ${ }^{6}$ for highpurity iron-carbon alloys, and by French and Klopsch ${ }^{7}$ for plain carbon steels. In the experiments by the former, the cooling rate between 1,470 and $1,290^{\circ} \mathrm{F}$ was determined by quenching thin wires of iron-carbon alloys in gas from about $1,800^{\circ} \mathrm{F}$. These alloys were prepared from carbonyl iron and carbon. French and Klopsch determined the critical cooling rate at $1,330^{\circ} \mathrm{F}$ for the centers of cylinders 0.5 inch diameter by 2 inches long quenched from about $135^{\circ} \mathrm{F}$ above $\mathrm{Ac}_{3}$ for hypoeutectoid steels and for about $135^{\circ} \mathrm{F}$ above $\mathrm{Ac}_{1}$ for hypereutectoid steels.

They found that the critical cooling rates of both the high-purity iron-carbon alloys and plain carbon steels decreased with increase in carbon content up to about eutectoid compositions, but with further increase in carbon the critical cooling rates also increased. That is, when both the iron-carbon alloy and plain carbon steel were of about eutectoid compositions, they had the minimum critical cooling rates (were deeper hardening) than the hypoeutectoid or hypereutectoid alloys and steels. These results were influenced, however, by variables other than the carbon content of the materials. These two investigations were made without due regard for the influence of austenitic grain size and, in addition, the quenching temperatures used by French and Klopsch were not sufficiently high to insure complete solution of all the carbon in the highest-carbon steel.

\section{SUMMARY}

High-purity iron-carbon alloys were prepared from hot- and coldworked specimens of a heat of vacuum-fused electrolytic iron by carburizing in a hydrogen-benzene mixture. The carburized specimens were heated and cooled in vacuo to obtain uniform distribution of the carbon. Cooling during this homogenizing treatment was sufficiently rapid to form sorbite (or fine pearlite) in all of the alloys. Microscopic examination of the cross sections of the bars of the different alloys showed the carbon to be uniformly distributed.

The alloys studied contained $0.23,0.40,0.50,0.62,0.73,0.80,0.85$, $1.01,1.14$, and 1.21 percent of carbon, respectively. These values are believed to be accurate within the limits of plus or minus 0.01 percent of carbon.

A series of plain carbon steels was also prepared by pack-carburizing specimens of a 0.20 -percent carbon steel followed by pack-annealing and normalizing. A second series of plain carbon steels was prepared by carburizing specimens of the same 0.20 -percent carbon steel in hydrogen and benzene and homogenizing by heating and cooling in vacuo.

The plain carbon steels varied in carbon from that of the basic material, 0.20 to 1.38 percent. These steels also contained about 0.46 percent of manganese and 0.15 percent of silicon.

\footnotetext{
${ }^{6} \mathrm{H}$. Esser, W. Eilender, and E. Spenle, Quenching diagrams of the iron-carbon alloys, Arch. Eisenhüttenw. 6, 389-393 (1935).

${ }_{7}^{7}$ H. J. French and O.Z. Klopsch, Quenching diagrams for carbon steels in relation to some quenching media for heat treatment, Trans. Am. Soc. Steel Treating 6, 251-294 (1924). $57763-38-2$
} 
Spectrochemical and chemical analyses, as well as determinations of gas content by a vacuum-fusion method, showed that sulfur, nickel, cobalt, and oxygen were the major impurities in the iron-carbon alloys. The total of all the impurities determined was about 0.030 percent.

Abnormal structures were produced in the hypereutectoid alloys annealed in vacuo at $1,700^{\circ} \mathrm{F}$.

All specimens used for determination of the austenitic grain size and critical cooling rate had an initial structure of sorbite (fine pearlite).

Austenitic grain size was determined for the highest-carbon alloy (1.21 percent of carbon) at a temperature sufficiently high to insure complete solution of all the carbon. Subsequent determinations on the lower-carbon alloys showed that variations in carbon did not affect the grain size at this selected temperature of $1,700^{\circ} \mathrm{F}$. Each of the alloys at $1,700^{\circ} \mathrm{F}$ had an average grain size of 6 to 12 grains per square inch at 100 diameters (ASTM grain number 4).

The carbon steel containing 1.18 percent of carbon had the same grain size as the alloys at $1,700^{\circ} \mathrm{F}$. Lower temperatures were necessary to establish the same austenitic grain size in the lower-carbon steels. On heating within the recommended hardening temperature range, specimens of the hypoeutectoid carbon steels had a constant average grain size of 12 to 24 grains per square inch at 100 diameters (ASTM grain number 5). No differences were observed in temperature-grain-size-critical-cooling relations of the carbon steels prepared by pack-carburizing and those carburized in hydrocarbon.

The critical cooling rate was taken as the average cooling rate, between 1,110 and $930^{\circ} \mathrm{F}$, which produced in the quenched specimen a structure of martensite with nodular troostite (fine pearlite) in amounts estimated to be between 1 and 3 percent.

The critical cooling rate was determined for each of the ironcarbon alloys quenched directly from $1,700^{\circ} \mathrm{F}$, and for the carbon steels varying in carbon from 0.43 to 1.18 percent, quenched also from the temperatures establishing a constant austenitic grain size with all carbon in solution.

For the selected conditions of constant austenitic grain size and solution of all carbon in the austenite, the critical cooling rate decreased continuously with increase in carbon, for both the high-purity iron-carbon alloys and plain carbon steels. That is, the hypereutectoid alloys had slower critical cooling rates (were deeper hardening) than the alloys of eutectoid and hypoeutectoid compositions, and the hypereutectoid steels were deeper hardening than the steels of eutectoid and hypoeutectoid compositions. However, a small change in the carbon content of the austenite of the lower-carbon alloys and steels had a more marked effect on the critical cooling rate than did a corresponding change in carbon of the high-carbon alloys and steels.

The carbon content of the austenite, therefore, had a pronounced influence on the hardenability of the alloys and steels. Under similar conditions with respect to austenitic grain size, carbon content, and with complete solution of the carbon in the austenite, the high-purity iron-carbon alloys hardened less deeply than did the plain carbon steels. This difference in hardenability was due principally to difference in manganese content of the alloys and steels. 
For the carbon steels quenched from the usually recommended hardening temperature, the critical cooling rate decreased with increase in carbon up to about 0.75 to 0.80 percent, but increased rapidly with further increase in carbon up to about 1.05 percent. Changes in carbon from about 1.05 to 1.40 percent had no appreciable influence on critical cooling rate. These critical cooling rates, however, were influenced by variations in austenitic grain size, and carbon content of austenite as well as the total carbon content.

Full depth of hardening was obtained only when all the carbon was in solution in the austenite.

J. A. Bennett, a member of the staff of this Bureau, assisted in assembling the apparatus shown in figure 1 and in carrying out the carburizing experiments with gases.

Washington, February 11, 1938. 